\title{
DOSSIÊ
}

Marilice Corona

\section{Território partilhado: cruzamento de linguagens, espaço de reflexão}

\section{Resumo}

Pintores contemporâneos como Mark Tansey e Michaël Borremans incluem a fotografia e o filme em suas práticas artísticas refletindo, em território partilhado e de modo autorreferencial, a inegável mediação tecnológica no qual nos vemos submersos. Este artigo tem como objetivo analisar de que forma, nesse cruzamento de linguagens, instaura-se um espaço de reflexão.

\section{Palavras-chave}

Pintura. Fotografia. Filme. Autorreferencialidade. Representação. 


\section{INTRODUÇÃO}

Como sabemos, a fotografia foi, durante o século XX, penetrando cada vez mais no ateliê dos pintores e hoje, mesmo tornando-se uma prática corriqueira, ainda parece ampliar e colocar questões à pintura. Pintores contemporâneos como o americano Mark Tansey (1949, San Jose, Califórnia) e o belga Michaël Borremans (1963, Geraardsbergen, Bélgica) incluem a fotografia e o filme em suas práticas artísticas refletindo, em território partilhado, a inegável mediação tecnológica no qual nos vemos submersos.

Seria possível dizer que estes artistas fazem parte de uma geração pós Gerard Richter. São artistas que questionam a pintura a partir de sua capacidade de produzir imagens de imagens, no entanto, suas obras não evidenciam nenhuma preocupação de caráter hiper-realista, ao modo dos americanos. Os pintores em questão estariam mais preocupados com a transposição para a pintura das qualidades materiais ou convenções dos meios de reprodução técnica do que com o aspecto de verossimilhança das imagens. De meu ponto de vista, para Borremans e Tansey não se trata de fazer uma fotografia com a mão, mas de determinar uma espécie de território partilhado onde encontramos uma confluência de convenções, no qual procuram evidenciar e manter a força expressiva da materialidade da pintura. Um território partilhado fundado e alimentado, grande parte das vezes, por procedimentos autorreferenciais.

A noção de território partilhado deverá ser entendida, aqui, não apenas como uma zona de cruzamento de linguagens, mas sim como um espaço reflexivo no qual o artista coloca em questão a própria linguagem que utiliza, discutindo os mecanismos da representação e o estatuto da imagem. Quando, em território partilhado, a fotografia ou o filme passam a fazer parte do processo de criação do pintor que novas questões trazem à pintura? E o diálogo entre esses meios levantaria quais questões?

\section{MARK TANSEY: UM SISTEMA DE OPOSIÇÕES}

A autorreferencialidade da arte, a consciência dos limites da pintura e, consequentemente, dos limites do espaço pictórico tratam-se de questões intrínsecas à linguagem da pintura ocidental. Procedimentos metapicturais 
expressivos já podem ser encontrados no século $\mathrm{XV},{ }^{1}$ quando surge o quadro único de cavalete. Com o passar do tempo, essas questões tornam-se princípios e são fortemente utilizados como fundamento pelas vanguardas modernistas. A partir do final dos anos 50, através do hibridismo de linguagens em contraposição à pureza dogmática do período anterior, percebe-se que tais questões continuam sendo desdobradas e discutidas de diversas maneiras, no entanto, de forma crítica e analítica. 0 questionamento sobre os limites da pintura, do espaço real e do ilusório, da apresentação e da representação, da manufatura e da reprodução mecânica, do potencial retórico e narrativo da linguagem, sua historicidade e o seu prolífico diálogo com outros meios estão muito presentes na pintura atual. Nesse sentido, a obra de Mark Tansey parece exemplar.

Tansey, filho de professores de história da arte, inicia seus estudos em pintura ainda adolescente no final dos anos 60 . Nos anos 70 , estuda com outros pintores e começa a trabalhar com ilustração. Neste momento, enquanto muitos críticos e artistas olhavam a ilustração com desconfiança, Tansey percebeu esta área como campo fértil para sua pintura. Além disso, tendo frequentado aulas com Rosalind Krauss, foi introduzido na séria disputa teórica entre estruturalistas e pós-estruturalistas (DANTO, 1992, p. 23). Segundo Taylor (1999, p.4), Tansey estava intrigado com as questões levantadas por estas teorias e rapidamente ficou absorvido e familiarizado com suas complexas ideias. Conforme o autor, para podermos apreciar a pintura de Tansey, precisamos estar a par do debate filosófico que dominava a literatura e a crítica da arte nos anos 70 e 80 . É por este viés, e principalmente através de Derrida, que Tansey discutirá a representação. Quando Mark Tansey começa a pintar, no final dos anos 70, trazendo para a pintura sua experiência como ilustrador, estava preocupado em reabilitar a imagem figurativa e redefinir a tarefa da representação (MÖNIG, 2005, p. 10-40).

Tansey utiliza-se de um sistema tradicional de representação para discutir a produção de imagens e a possível inter-relação dos vários meios de reprodução destas. Através de um método subtrativo, adicionando óleo e pigmento sobre a tela gessada, faz surgir suas imagens através do ato de raspar estas substâncias para reencontrar a luminosidade do branco do suporte. Como bem comenta o artista, a presença do monocromatismo em suas pinturas deriva das relações que este estabelece com a imagem fotográfica, bem como com o arcabouço conceitual que ele opera.

No princípio, eu fui atraído para o monocromatismo - preto e branco - porque tudo que eu gostava estava nele, de reproduções de Michelangelo à ilustração científica e fotografias da revista Life. Esta simples, mas versátil sintaxe, foi compartilhada pela arte, ficção e realidade fotográfica, ela tornou possível outro nível de ficção pictórica onde aspectos de cada um poderiam se unir. Um quadro pintado já não
1. Procedimentos metapicturais já são encontrados na Antiguidade mas passam a ser utilizados de modo mais expressivo a partir do século XV. Ver: GÁLLEGO, J. El quadro dentro del quadro. Madrid: Ediciones Cátedra, 1984. 
tinha que fingir a não-ficção, já não tinha que ser uma gaiola para o real, tornando-se possível pensar em termos de um campo conjetural ou lugar de investigação. 0 quadro poderia trabalhar com uma forma híbrida equidistante entre as funções da pintura, da ilustração e da fotografia. Em minhas pinturas iniciais, minha preocupação primária era descobrir como reunir imagem e idéia. Comecei oposições simples: masculino/feminino, artificial/natural, estático/móvel, mítico/científico, presente/ passado. Descobri que oposições de claro e escuro poderiam agir como um análogo formal a oposições conceituais. (TANSEY, 1992, p.128).

A pintura de Tansey coloca-nos inúmeras questões: a percepção e memória tátil em oposição à visual; as raspagens e as marcas como modo indicial de significação; disparidades e justaposições temporais; inter-relação entre pintura e meios mecânicos de produção de imagens; realismo e representação; aliança entre conceitual e formal. Em vista disso, percebe-se que os procedimentos técnicos do pintor estão intimamente vinculados com o arcabouço conceitual da obra sendo que a materialidade e as características específicas da imagem fotográfica de referência geram novas estratégias para a pintura.

Grande parte dos artistas reúne em torno de si uma gama de imagens ou objetos. Alguns destes artistas são mais atentos e organizados quanto ao material colecionado. Tansey refere-se aos seus documentos como biblioteca de imagens, onde reúne metodicamente um manancial heterogêneo de imagens que, como já foi dito, vão desde reproduções de pinturas dos grandes mestres a ilustrações científicas e fotografias retiradas das revistas Life. Para o artista, "colecionar imagens é aceitar, como recurso, representações da experiência humana de muitas culturas e tempos - como também de nossas experiências diretas e indiretas" (TANSEY, 1992, p. 128).

Tansey utiliza-se de uma máquina fotocopiadora, o que lhe permite uma grande liberdade em recortar e montar suas colagens que servirão de referência às pinturas. Em uma mesma montagem, reúne figuras, texturas e paisagens de origens distintas que, no entanto, ao serem transpostas para a pintura assumem um caráter homogêneo. Encontramos nos procedimentos preparatórios de Tansey semelhanças com os procedimentos empregados pelo pintor realista americano Thomas Eakins (1844-1916), que já no final do século XIX fez grande uso da fotografia e da colagem misturadas ao desenho para elaborar suas pinturas. No caso de Tansey, além de toda a relação retórica construída através do jogo entre as imagens, o artista transpõe para a pintura, por exemplo, a coloração antiga das imagens e ilustrações de revistas e jornais dos anos de 1950.

A referência temporal aos anos 50 não é sem razão, pois grande parte do conteúdo retórico de suas obras trata da crítica aos postulados de Clement Greenberge a Escola de Nova York. São inúmeras as pinturas em que reúne personagens do universo da arte de diferentes épocas. Veja-se Mith of depth (1984). 
Em a Short history of modernist painting (1979-80), encontramos uma coleção de imagens cujas origens são as mais diversas. À primeira vista tal pintura pode apresentar-se como mera colcha de retalhos. No entanto, um olhar mais atento passa a perceber a rede de significações construída pelo artista. Conforme Sims, as imagens de referência utilizadas nessa pintura foram retiradas de revistas variadas como a Popular Mechanics, a National Geographic, de periódicos militares como o Soldier of Fortune, revistas de cinema e a já citada revista Life. Segundo o autor, Tansey estava particularmente atraído pelas imagens da Popular Mechanics por que ele sentia que a ideologia da revista, baseada no "faça você mesmo", "no autoaperfeiçoamento, progresso e resolução de problemas correspondia diretamente à dialética modernista" (SIMS, 1990, p.12). O artista dividiu a estrutura quadrangular de Short History... em faixas de duas cores: algumas na escala de tons do branco ao preto e outras em tons de sépia. A imagem de referência foi composta por 51 fotografias recortadas de revistas e, posteriormente, coladas lado a lado, em faixas, formando a estrutura de um quadrado. Para cada linha horizontal, Tansey determinou um fio condutor conceitual para as imagens. "Começando pelo topo, as sete faixas foram organizadas em torno dos seguintes assuntos e temas: janela, porta, obstáculo, estabelecimento de chão, superfície e suporte, autorrepresentação e análise, o alvo e olhar" (SIMS, 1990, p.14). Temas e assuntos que alegorizam, de forma metapictural, as discussões históricas sobre pintura e representação.

O monocromatismo e a temporalidade impressa nas fotografias de referência, quando transpostos para a pintura, são elementos indispensáveis para a construção da narrativa de Tansey. Exemplares são as pinturas Action Paintig (1981) e Action Painting II (1984).

Em Action Painting observamos uma pintora em traje de passeio bastante datado (amadora, talvez) executando uma pintura de observação, ao plein-air, de um acidente automobilístico. Aqui temos uma série de colisões de sentido e interpolações de tempo. Em primeiro lugar, a começar pelo título, o pressuposto da action paiting tratava-se de prescindir do modelo. A ação, o gesto e a espontaneidade eram suas bases. Aqui a ironia reside no transporte da ação do pintor para a ação contida no assunto observado. Ao mesmo tempo, o que vemos colidir é a estrutura temporal da pintura com a temporalidade relâmpago do evento observado. 0 braço estendido, tão nosso conhecido, busca medidas e proporções. Tenta interpretar o modelo em uma velocidade incompatível ao de um acidente. Esse "instante decisivo" cujo registro só poderia ser captado pela fotografia ou outro dispositivo mecânico. Conforme o próprio artista declara,

Esta estrutura triplamente codificada reúne o tempo fotográfico (o próprio acidente visto em ação separada); o tempo que se leva para fazer uma imagem à mão (o pin- 
tor que registra o acidente); e o tempo que eu levei para fazer a pintura. 0 ponto aqui não é celebrar o absurdo ou se divertir dentro do surreal, mas procurar as relações entre estruturas de tempo e os limites de vários meios de representação. (TANSEY, 1992, p.128).

Seria possível dizer que essa pintura coloca em questão não somente as especificidades temporais dos diferentes meios de produção de imagem, mas o auxílio que um meio traz a outro na discussão sobre a representação. Como espectadores, somos colocados também em posição auto-reflexiva diante da pintura, pois, a mis en abyme do quadro dentro do quadro, somado ao desconcerto que nos traz a colisão temporal, nos faz refletir sobre a própria mediação no qual nos vemos constantemente submetidos. Mediação sempre atravessada por suas próprias convenções.

A obra de Mark Tansey, inserida na "cultura fotográfica" e em diálogo com essa contingência, abre um campo vasto de significações que extrapolam os elementos tidos como "fundamentais" da linguagem pictórica (o plano, o gesto e a cor). Em território partilhado, o artista reabilita e atualiza as antigas funções da pintura de forma crítica e provocadora.

\section{MICHAËL BORREMANS: A REPETIÇÃO COMO ESTRATÉGIA}

Michaël Borremans (1963), vive e trabalha em Gante, na Bélgica. Começa a pintar em 1993 e hoje é considerado um dos mais importantes pintores contemporâneos ao lado de seu conterrâneo Luc Tuymans. Sobre seus temas, ao contrário de Tansey, não encontramos uma narrativa conclusiva. Suas pinturas são enigmáticas. Assemelham-se a códigos que não conseguimos decifrar. Suas figuras habitam espaços indefinidos ou são representadas, na maioria das vezes, sobre fundos chapados de cor. Tais fundos remetem-nos ao fundo infinito dos estúdios fotográficos ou às figuras recortadas de Manet, a quem faz referência de modo indireto. Lembremos aqui de $O$ tocador de pífaro. Muitos autores tentam vinculá-lo à tradição surrealista belga, principalmente fazendo referência a Magritte. Essa aproximação pode ser justa, principalmente, no que concerne às proposições autorreferenciais que colocam os mecanismos da representação em cheque. Como teria comentado Sardo,

De fato, existe uma possível conotação em relação ao surrealismo na pintura de Michaël Borremans, mas ela não é oriunda de uma relação onírica do sentido, mas de um uso da repetição como dispositivo, presente na forma recursiva como as mesmas situações surgem no desenho, na pintura e, por agora também, nos filmes. Essa repetição é utilizada de duas formas: pela recorrência do gesto representado (moldar, escavar, arrumar, mexer, ordenar), mas também pela sucessividade de situações que migram de suporte para suporte, contraindo ou dilatando a estrutura temporal. (SARDO, 2007, p.37). 
Diria ainda que a repetição está colocada em detalhes que caracterizam suas figuras. Tanto em suas pinturas como em seus filmes, boa parte delas parece trajada e despersonalizada com uniformes; funcionários de não se sabe o quê estão envolvidos em ações mecânicas, repetitivas, vazias de sentido. A sensação que se tem é de estarmos diante de cenas de uma sociedade de autômatos, sempre sob controle. Penso aqui em 1984 de Orwell e, ainda mais, em Alphaville, de Godard. Outro aspecto relevante e, que remonta a alguns procedimentos do surrealismo, é a presença do duplo como uma constante em suas obras. Figuras fabricam ex-votos de si ou carregam no colo o simulacro de seu próprio corpo. 0 estranhamento e desconforto causados por suas imagens estão vinculados, entre outras coisas, a tudo que evoca em nós a imagem do duplo. Como teria afirmado Rogiers com relação aos gêmeos, ao mesmo tempo em que nos causam extremo fascínio por sua aparência idêntica, "eles encarnam o tormento da identidade, a incerteza de ser, realmente, si mesmo" (ROGIERS, 1998, p. 7). A inquietante estranheza descrita por Freud tem aí suas bases, ou seja, na relação ambígua que nós mantemos com nossa própria imagem.

A repetição em Borremans não se dá apenas no âmbito da representação, mas no modo como articula e explora as propriedades dos meios que utiliza, bem como na forma de apresentação do conjunto das obras no espaço de exposição. Reunindo desenhos, pinturas e tableaux vivants (assim chamados seus filmes) em um mesmo espaço, o artista intenciona evidenciar como as diferentes linguagens se intercomunicam em seu processo de trabalho. Em sua retrospectiva Eating the bread, em Stuttgart, em maio de 2011, podíamos encontrar o rebatimento entre a pintura The Skirt, 2005, o filme Weight, 2005, os desenhos Drawing, 2002, e Skirtsculpture, 2005. Devido a esse rebatimento é possível observar como a linguagem da pintura é determinante na criação e resultado de seus filmes. A repetição dos motivos também é realizada em uma mesma linguagem. Uma das estratégias do artista é trabalhar em séries de pinturas que se correlacionam. Em um certo sentido, tal estratégia relaciona-se com a natureza sequencial dos fotogramas.

No princípio, as imagens de referência de Borremans eram retiradas de revistas, postais, filmes, imagens baixadas da internet, e outras imagens prontas. No documentário A knife in the eye, quando questionado por seu entrevistador se a fotografia era necessária como ponto de partida para sua pintura, 0 artista responde:

Bem, há uma tradição nisso desde a origem da fotografia. Tão logo ela surgiu, os pintores já fizeram uso dela. Em meu caso, no princípio, costumava trabalhar com materiais que eu encontrava e recuperava, mas, eu adicionava coisas à imagem ou me distanciava dela. Eu nunca copiei a fotografia, sempre manipulei a imagem quanto à 
luz, cor ou composição. Mesmo se você, conscientemente, não a manipula, quando você pinta você sempre manipula quer queira quer não. (BORREMANS, 2011).

Em 2002 Michaël Borremans começa a fazer suas próprias fotografias a partir de imagens captadas da tela de TV. Essa experiência leva-o a construir um estúdio fotográfico em seu ateliê e inicia, assim, um novo processo de criação, fotografando modelos em um ambiente neutro, onde passa a ter todo controle sobre a imagem, determinando a qualidade de luz e de toda mis en scene que irá transpor para a pintura. Nesse caso, determina a qualidade de luz muitas vezes a partir de referências advindas da história da pintura, como a luz de Caravaggio, Velázquez e outros. A cena a ser fotografada é cuidadosamente composta em função do que deseja obter em pintura. Os figurinos, objetos e acessórios são confeccionados especialmente para compor a cena e expressar o conceito subjacente à imagem. Sendo assim, a representação da representação, aspecto recorrente nas obras de Borremans, parece assumir ainda mais força.

O filme, por sua vez, tem exercido papel importante na obra de Borremans. Se no princípio o artista servia-se de imagens fílmicas para suas pinturas, mais recentemente tem realizado filmes impregnados de beleza pictórica e silêncio. Em uma entrevista publicada em Art in America o artista comenta:

0 que eu tento fazer com filmes vem das pinturas. Enquanto pinto, tenho o sentimento de que necessito de um diferente elemento de luz ou movimento. Meu interesse pelo filme já estava presente desde que era jovem. Então comecei a experimentar. The Storm (2006) é uma projeção em $35 \mathrm{~mm}$ de uma imagem viva. Mas o trabalho ainda é mais pintura do que filme. 0 médium é filme, mas a maneira que eu o abordo é pintura. (BORREMANS; COOGINS, 2009)

Borremans diz preferir os filmes em 16 ou $35 \mathrm{~mm}$ ao invés do vídeo. Diz estar interessado na granulação da imagem por estar mais próxima das qualidades pictóricas. Além disso, afirma estar interessado no que a linguagem cinematográfica proporciona como, por exemplo, a possibilidade da imagem entrar e sair de foco. Michaël Borremans não está interessado em explorar de forma pura as especificidades dos meios que utiliza em função de uma ideia de demarcação de territórios, ao contrário, investiga suas especificidades para melhor intercambiá-las com o intuito de questionar e expandir seus limites. É no uso concomitante dos vários meios de produção de imagem e, também, no cruzamento desses meios que Borremans aborda questões sobre a representação, a semelhança, a unicidade e a multiplicidade, a originalidade, a autoria e a repetição e outros pontos caros à história da pintura e, por que não dizer, à história do conhecimento.

O filme The Storm apresenta-se como exemplar no que se refere à influência da pintura sobre o meio fotográfico, bem como, sobre as inversões empreendidas 
pelo artista em relação às características da linguagem fílmica e do que dela esperamos. 0 filme, projetado em uma grande área de parede do espaço expositivo, tem $1 \mathrm{~min} 07 \mathrm{~s}$ e é colocado em loop como todos os seus filmes. Trata-se de uma cena única e circular. A cena apresenta três homens negros sentados, vestidos com trajes de cetim branco brilhante, absolutamente imóveis. Estão apenas lá, sentados, uniformizados, respirando. A sensação de espera que habita a cena é a mesma que nos atinge. Diante de um filme esperamos movimento, ação, som, narrativa, no entanto o artista frustra nossas expectativas. 0 único elemento que atua na cena é a luz que pisca de modo lento e intermitente, fazendo surgir e desaparecer a imagem. A luz aqui assume o papel da tinta. Na sala de projeção o que ouvimos é o som do projetor que acompanha a respiração dos personagens. Conforme comenta Borremans (2009, p. 2), "o ritmo dos filmes é muito importante. Ele tem que ser tão lento quanto à respiração".

Quanto ao modo de apresentação, The Storm é um dos poucos filmes apresentados em grande projeção, pois, na maior parte das vezes são apresentados em tela plana, em LCD, em pequenas dimensões e emoldurados por molduras de madeira. Essa estratégia, associada à similaridade de cor e luz empregadas nas diversas linguagens, aproxima-os ainda mais das pinturas e atualiza um gênero artístico e de entretenimento em voga no século XVIII e XIX, na Europa, o tableau vivant. O tableau vivant trata-se de um gênero poroso de arte quanto às fronteiras que lhe delimitam. Situa-se no cruzamento entre o teatro, os jogos de sociedade, a pintura, a escultura (e, mais tarde, a fotografia), sendo tanto do domínio da história social, como da história do teatro e da história da arte (VOUILLOUX, 2002, p. 24). Segundo Bernard Vouilloux,

Este espetáculo consistia na representação exata, com a ajuda de seres animados, mas imóveis, de quadros ou grupos de esculturas célebres e conhecidos de todos. Para os quadros, os personagens eram vestidos em trajes cujos detalhes e cores eram reproduzidos com o maior cuidado; para as esculturas, eles eram todos cobertos com maiôs e tecidos drapeados brancos. Os agrupamentos e as poses eram naturalmente observados com a mais rigorosa exatidão e, quando a cortina se levantava sobre um quadro desse gênero, o efeito era impressionante. Este efeito era notável, sobretudo, para a escultura, que se podia apreciar sob todos os seus aspectos uma vez que os personagens eram colocados sobre uma superfície giratória que se movia lentamente sob os olhos dos espectadores. (VOUILLOUX, 2002, p. 26).

De meu ponto de vista, Borremans alcança o completo cruzamento de linguagens e a atualização dos tableaux vivants em sua obra Weight, 2005. 0 filme origina-se de um desenho de Borremans de 2002, intitulado Drawing, cuja imagem, por sua vez, deriva-se de uma fotografia encontrada em uma revista de tricô ${ }^{2}$ e que ainda terá desdobramentos em outras linguagens como a pintura e a escultura. A partir desse desenho, o artista vai em busca de uma modelo,
2. "Esta representação de uma jovem menina que adota uma pose majestosa, as mãos nas costas e 0 olhar fixo para frente, tem sua origem em uma fotografia encontrada em uma revista de tricô. Borremans, no entanto, modificou o motivo do tricô. No lugar desse, desenhou duas vezes o logo do governo flamengo, uma vez no sentido habitual (voltado para a direita) e outra vez no sentido invertido. Se a presença das duas feras sobre o pulôver acentua o caráter heráldico e emblemático do leão (flamengo), ela lhe faz, igualmente, perder sua soberba." Em nota 0 autor comenta o uso irônico que Borremans faz desse detalhe em função de uma obrigatoriedade imposta pelo governo de inserir o brasão em qualquer material gráfico e de divulgação de projetos de arte subvencionados pelo mesmo. Ver MARTENS, 2014, p. 34. 
3. "Termo alemão para sósia ou duplo de uma personagem, uma espécie de alma gêmea ou mesmo um fantasma que persegue um indivíduo, confundindo-se com a sua própria personalidade. 0 nome Doppelgänger se originou da fusão das palavras alemãs doppel (significa duplo, réplica ou duplicata) e gänger (andante, ambulante ou aquele que vaga). [...] 0 Doppelgänger nunca é visto por ninguém a não ser pelo seu portador. Não se vê ao espelho, não se mostra a mais ninguém para além da nossa mais perturbadora auto-consciência. A ideia de um sósia ou duplo fantasmagórico pode não envolver uma relação tão íntima entre 0 doppelgänger e 0 seu portador. Em termos menos abstratos, podemos falar desta relação quando uma personagem se inscreve na história literária com um nome que tem já uma tradição, e que se lhe apresenta como um fantasma sempre incômodo." Ver em E-Dicionário de termos literários de Carlos Ceia 2010. Disponível em: <http://www. edtl.com.pt/index.php?option=com mtreeधtask=viewlink\&link id $=765$ \&ltemid $=2>$. Acesso em: 02 set. 2012. 0 Doppelgänger é um termo que se notabilizou na literatura alemã do século XIX. Nas lendas populares, a visão do seu Doppelgänger era sinal de mau presságio. Sinal de sua própria morte. na mesma faixa etária, reproduzindo suas vestimentas tal como aparece na foto. Em seu estúdio constrói toda mis en scene que será filmada em $16 \mathrm{~mm}$ para, posteriormente, ser transferida para DVD. Em uma pequena tela plana (15" LCD) colocada verticalmente, uma menina gira lentamente, com os olhos fixos no infinito, encaixada sobre um pódio giratório negro no qual suas pernas desaparecem completamente. A exemplo das esculturas dos tableaux vivants do século XIX, a menina transforma-se em estátua. A rigidez e imobilidade desse corpo, cujas pernas apresentam-se amputadas, nos atravessa de forma violenta. Essa imagem, cuja duplicidade dúbia entre animado/inanimado ou, como teria apontado Sardo, "essa espécie de fantasma da morte que espreita na categoria do doppelgänger", ${ }^{3}$ intimamente ligada a ideia de autômato, vem abalar nossa vulnerável certeza de identidade e liberdade. Em território partiIhado, através do movimento circular determinado por suas imagens-enigmas, Borremans cria um espaço de jogo apostando no arcabouço de imagens-modelos que nos acompanha de modo inconsciente.

\section{CONCLUSÃO}

Michaël Borremans e Mark Tansey são pintores figurativos que revisitam a história da pintura, dialogam, questionam e utilizam diversos meios de produção de imagens. $O$ trânsito contínuo entre linguagens funda um espaço de reflexão, nos dois sentidos que o termo pode abarcar. Esse espaço, que denomino território partilhado, tem como principal função discutir os mecanismos da representação e a dimensão política que as imagens carregam. Na obra desses dois artistas encontramos várias camadas de informação: o que se vê não é somente o que se vê. Tansey discute a representação e faz a crítica aos sistemas reguladores da arte. Com perspicácia põe em cheque nossa vã tentativa de apreensão da realidade, demonstrando que esta seria a principal função da representação. Borremans, por sua vez, tem consciência do peso histórico da pintura. Desenvolveu uma habilidade técnica incontestável, sendo comparado, pela crítica, aos grandes mestres do passado. Compreendeu Velázquez e Manet sem acomodar-se em mero virtuosismo. 0 artista recorre à história da pintura e discute o poder da imagem nos dias atuais. Transitando por diferentes meios, suas imagens-enigmas discutem a linguagem que as configura ao mesmo tempo em que coloca em questão a história e a configuração social e política de seu país de origem. São imagens cujo estranhamento nos leva a pensar sobre a organização de poderes a qual todos nós estamos submetidos. 


\section{REFERÊNCIAS}

BORREMANS, Michaël; COOGINS, David. Interview: Michaël Borremans. Art in America, New York, 3 jan. 2009. Disponível em: <http://www.artinamericamagazine.com/ features/michael-borremans/>. Acesso em: 2011. Entrevista realizada por David Cooggins.

MICHAËL Borremans: A knife in the eye. Disponivel em: <https:// www.youtube.com/watch?v=dhhUmwmIMtc>. Documentário de Guido De Bruyn.

DANTO, Arthur. Mark Tansey: visions and revisions. New York: Harry N. Abrams, 1992.

MARTENS, Hans. Weight. In: Michaël Borremans: as sweet as it at. Bruxelas, Hatje Cantz, 2014.

MÖNIG, Roland. The picture looking back. In: MARK Tansey. Bielefeld: Kerber, 2005.
ROGIERS, Patrick. Avant-propos. In: L'ÈRE du double: actes du colloque sur la gemellit. Paris: Marval, 1998. p. 7-9.

TAYLOR, Marc C. The Picture in question: Mark Tansey and the ends of representation. Chicago: The University of Chicago Press, 1999.

SARDO, Delfim. In: VAN DUYN, Edna (Ed.). Michaël Borremans: Weight. Berlin: Hatje Cantz, 2007.

SIMS, Patterson. Art and source. Seatle: Seatle Art Museum, 1990.

VOUILLOUX, Bernard. Le tableau vivant: Phryné, l'orateur et le peintre. Paris: Flammarion, 2002.

\section{Marilice Corona}

Artista plástica formada em Pintura (1988) e Desenho (1990) pelo Instituto de Artes da Universidade Federal do Rio Grande do Sul, com mestrado (2002) e doutorado (2009) em Poéticas Visuais pelo PPGAV/UFRGS, Programa de Pós-Graduação em Artes Visuais da mesma instituição. Professora do Departamento de Artes Visuais e do PPGAV/UFRGS. Dedicando-se principalmente à linguagem da pintura, realizou diversas exposições individuais e coletivas no país e no exterior. Desde o ano de 2010 faz parte do conselho editorial das revistas Estúdio, Gama e Croma publicadas pela FBAUL, Faculdade de Belas-Artes de Lisboa, Portugal; em 2015 passa a integrar o comitê editorial da revista Porto Arte, PPGAV/UFRGS. 
Dossiê 